\title{
Role of diagnostic hysteroscopy and histopathology in evaluation of abnormal uterine bleeding
}

\author{
Hatem H. El-Gamal, Magda M. Abd-El-Salam, Reda M. Ghanem, Shaymaa I. Al-Ani \\ Department of Obstetrics and Gynecology, Faculty of Medicine - Ain Shams University \\ Corresponding author: Shaymaa I. Al-Ani; Mobile: 01068019982; Email: shaimaa.alani@yahoo.com
}

\begin{abstract}
Background: Abnormal uterine bleeding is a bleeding from uterine compose that is abnormal in volume, regularity and/or timing that has been present for the majority of the last 6 months. Evaluation of women with abnormal uterine bleeding should comprise history taking, systemic and local examination, laboratory investigations, imaging and different diagnostic procedures including hysteroscopy. Aim of the Work: to assess the accuracy of hysteroscopy in the diagnosis of the cause of bleeding in women with abnormal uterine bleeding. Patients and Methods: This prospective observational study was conducted on 114 patients attended the Early Cancer Detection Unit, Faculty of Medicine, Ain Shams University between July 2017 and April 2018, to assess the role of diagnostic hysteroscopy and histopathology in evaluation of abnormal uterine bleeding. Results: Hysteroscopy had a sensitivity of $91.9 \%$, specificity of $86.5 \%$, positive predictive value of $93.2 \%$, and negative predictive value of $84.2 \%$ and diagnostic accuracy of $90.1 \%$ for diagnosing the etiology of abnormal uterine bleeding. Conclusion: Hysteroscopy has a definitive role in evaluating patients with abnormal uterine bleeding especially with patient with thick endometrium, in any age group. Hysteroscopy is a safe and reliable procedure in the diagnosis of cases with abnormal uterine bleeding with high sensitivity, specificity, positive predictive value and negative predictive value and the results of hysteroscopy are immediately available. Hysteroscopy and histopathology complement each other in evaluating patients with abnormal uterine bleeding for accurate diagnosis and further treatment.
\end{abstract}

Key words: Hysteroscopy, Histopathology, Uterine Bleeding

\section{INTRODUCTION}

Abnormal uterine bleeding is a bleeding from uterine compose that is abnormal in volume, regularity and/or timing that has been present for the majority of the last 6 months. It may be excessively heavy or light and may be prolonged, frequent, or random ${ }^{(\mathbf{1})}$.

Abnormal vaginal bleeding is a common complaint in primary care. The prevalence of some type of abnormal bleeding is up to $30 \%$ among women of reproductive age ${ }^{(2)}$.

Over $18 \%$ of all gynecology outpatient visits in the United States are for menorrhagia alone ${ }^{(3)}$.

Because most cases are associated with anovulatory menstrual cycles, adolescents and perimenopausal women ${ }^{(4)}$ are particularly vulnerable. About 20\% of affected individuals are in the adolescent age group, and 50\% of affected individuals are aged $40-50$ years.

In 2011, the International Federation of Gynecology and Obstetrics (FIGO) published a new classification system and the American College of Obstetrician-Gynecologists has also endorsed this new classification system ${ }^{(5)}$.

This system divides the etiology of abnormal uterine bleeding into structural and non-structural causes and follows the acronym PALMCOEIN. New nomenclature uses the acronym of AUB (abnormal uterine bleeding) with the initial from the classification system as a description of the disorder (e.g. abnormal uterine bleeding caused by ovulatory disorders is referred to as AUB-O). The term dysfunctional uterine bleeding, used in the past to describe abnormal bleeding, is being replaced by these terms. Differential diagnosis will vary based on symptomatology as well as age. Pregnancy is a possible cause of any type of abnormal bleeding in any woman of reproductive age (ie, after menarche and before menopause). Many systemic illnesses and medications can affect menstrual bleeding and should be included in a broad differential diagnosis of a presenting woman ${ }^{(6)}$.

Until recent times, usual method of evaluating this symptom was dilatation and curettage. But this detects the cause in less than $50 \%$ of the cases. Hysteroscopy offers a valuable extension of the gynecologist's armamentarium. It can improve the diagnostic accuracy and can permit better treatment of uterine diseases. After hysteroscopy, the elective surgery of the patient can be planned better ${ }^{(7)}$.

Hysteroscopy allows direct visualization of the endometrial cavity and importantly, directed endometrial sampling of any suspicious areas ${ }^{(8)}$.

Use of hysteroscopy in abnormal uterine bleeding is almost replacing blind curettage, as it "sees" and "decides" the cause. This is because the uterine cavity can be observed and the area in question can be curetted. In fact, it is an eye in the uterus ${ }^{(9)}$. 


\section{AIM OF THE WORK}

This study aims to assess the accuracy of hysteroscopy in evaluation of abnormal uterine bleeding and to correlate hysteroscopic findings with histopathologic findings.

\section{PATIENTS AND METHODS}

\section{A- Study Type:}

This study is a prospective observational study conducted on 114 patients attended the Early Cancer Detection Unit, Faculty of Medicine, Ain Shams University between July 2017 and April 2018, to assess the role of diagnostic hysteroscopy and histopathology in evaluation of abnormal uterine bleeding. The study was approved by the Ethics Board of Ain Shams University and an informed written consent was taken from each participant in the study.

Patients Selection Criteria: Sample Size Justification: Sample size was calculated using nomogram for sample size estimation using diagnostic test accuracy indices (10), setting the absolute precision (L) at 0.07 and the confidence level at 0.95. Data from a previous report (11), indicated that hysteroscopy had a sensitivity of $93.2 \%$ and a specificity of $83.9 \%$ with disease prevalence of the most common abnormality of $27 \%$. Calculation according to the previous data to achieve the anticipated sensitivity and specificity produced a minimal sample size of 114 to achieve the anticipated sensitivity and 56 to achieve the anticipated specificity. Assuming that in our study sensitivity and specificity are equally important, a sample size of 114 patients were used. MedCalc ${ }^{\circledR}$ version 12.3.0.0 program was used for calculations of sample size, statistical calculator based on $95 \%$ confidence interval and power of the study $80 \%$ with $\alpha$ error $5 \%$.

\section{B- Study Entry and Duration:}

Recruitment: During the pre-selective visit, inclusion and exclusion criteria were applied. Careful history was taken including nature and severity of vaginal bleeding and symptoms suggesting possible significant pathology. Physical examination (both general and local pelvic) was performed.

Study Duration: Study duration was 6 months from July 2017 to April 2018.

\section{C-Selection of Patients}

Inclusion Criteria: Age: 20 - 50 years of age with abnormal uterine bleeding due to structural causes. Written and signed informed consent by the patient to participate in the study.Multiparous and nulliparous women with abnormal uterine bleeding who will not require any emergency management at the time of the study.

Exclusion Criteria: Patient with severe anemia due to menorrhagia. Professed vaginal bleeding. Suspected pregnancy. Patient unwilling to participate in study. Patient with tight or closed cervical os.

\section{E- Data Collection and Schedule:}

Enrollment (recruitment) Data: Following admission, all patients underwent complete clinical examination and detailed medical history was obtained. Each patient had a case report form (CRF) in which the following data will be recorded: Patient initials. Patient number. Previous deliveries and operations. Age, height, weight and BMI. Past medical and surgical history. Menstrual history. Nature and severity of vaginal bleeding, Symptoms suggesting possible significant pathology. Clinical examination: including general, abdominal and pelvic examination. Result of pelvic sonography.

\section{F- Method protocol}

Ethical Considerations: After selection of the participants, the purpose of the study was adequately explained to each participant, all participants signed an informed consent after explaining them the objective of the study.

Approvals: Before the beginning of the study and in accordance with local regulation followed, the protocol and all corresponding documents were declared for ethical research approval by the council of OB/GYN department, Ain Shams University.

\section{All patients were subjected to the following:}

a- Detailed History: including the following points: Present history of bleeding including onset, course, duration, and criteria of bleeding pattern. History of recent hormonal contraception and particular drug intake. History of bleeding tendency or general cause of bleeding. Past history of operations or blood transfusion. Family history of similar condition.

b- General examination: Weight, height, BMI, general appearance. Vital signs (blood pressure and pulse), pallor and manifestations of anemia.

c- Local examination: Inspection of external genitilia. Bimanual examination to detect uterine size, mobility, axis, tenderness and adnexal masses.

\section{d- Pelvic ultrasound report.}




\section{G- Hysteroscopy Evaluation:}

Diagnostic hysteroscopy was conducted outside of the formal operating theatre setting in an appropriately sized, fully equipped and staffed treatment room with adjoining, private changing facilities and toilet, in Early Cancer Detection Unit / Al Demerdash Hospital. Diagnostic hysteroscopy was carried out by a professional, skilled and expertise examiner. An assistant nurse was available. Written patient's information was provided before the appointment and consent for the procedure were taken.

Women without contraindications advised to take standard doses of non-steroidal antiinflammatory agents (NSAIDs), Diclofenac sodium supp. $100 \mathrm{mg}$, around one hour before their scheduled outpatient hysteroscopy appointment with the aim of reducing pain in the immediate postoperative period

We used a rigid continuous flow 30" hysteroscopy, with an outer sheath of $2.9 \mathrm{~mm}$. The technique provided a constant uterine distention by attaching plastic bags of saline $0.9 \%$ to dual infusion tubing. The cavity was explored looking for polyps, masses, myomas or polyploidy endometrium.

The light source used in this study is a fiber optic light cable, with straight connector, diameter 2 . $5 \mathrm{~mm}$, length $180 \mathrm{~cm}$.

Distension of the uterine cavity was needed by attaching plastic bags of saline solution $0.9 \%$, at a pressure of 200- $120 \mathrm{mmHg}$ with the aim to use the lowest pressure required to distend the uterine cavity adequately.

The procedure was monitored using a singlechip video camera, and the image is displayed on a monitor visible to the operator. The camera has a focal length varying from F70 to F 140.

The hysteroscopy picture which appeared through the optic was transmitted on the monitor by the camera which was fitted to the eyepiece of the optic where the 30" diagnostic hysteroscopy could be performed with better visualization and accuracy.

\section{4- Statistical analysis:}

Data were statistically described in terms of range, mean \pm standard deviation $( \pm \mathrm{SD})$, median, frequencies (number of cases) and percentages when appropriate. Agreement between US, hysteroscopy diagnosis and endometrial sampling diagnosis was done using kappa statistic. For comparing categorical data, Chi square $(\chi 2)$ test was performed. Exact test was used instead when the expected frequency is less than 5. $\mathrm{p}$ values less than 0.05 was considered statistically significant. All statistical calculations were done using computer programs SPSS (Statistical Package for the Social Science; SPSS Inc., Chicago, IL, USA) version 15 for Microsoft Windows.

Accuracy of hysteroscopy was examined using 2-by-2 contingency tables with histopathological diagnosis used as the gold-standard test as follows:

\begin{tabular}{|l|c|c|}
\hline & \multicolumn{2}{|c|}{ Histopathology (Gold-standard) } \\
\hline Hysteroscopy (Test) & Positive & Negative \\
\hline Positive & TP & FP \\
\hline Negative & FN & TN \\
\hline
\end{tabular}

\section{RESULTS}

Hysteroscopy was performed in 114 women presented with abnormal uterine bleeding followed, hysteroscopic biopsy was taken. The specimen was sent for histopathological examination. The hysteroscopic and histopathologic patterns were studied, and the measures of validities were computed taking histopathology as the gold standard. Three cases were excluded from the study due to inadequate sample and autolysis. So the study completed with 111 cases.

One hundred and fourteen women were enrolled in this study. Their mean (SD; 95\% CI) age was 41+/-9 years; mean body mass index (BMI) was $27 \pm 2(22-32)$, Duration of marriage (years) was $20.5 \pm 10.8(0.2-40)$ and mean parity was $3(0-10)$ while miscarriage was $0(0-4)$ (Table 1$)$.

Table (1): Demographic data for the whole study population.

\begin{tabular}{|l|c|c|}
\hline \multicolumn{1}{|c|}{ Variable } & $\begin{array}{c}\text { Mean } \pm \text { SD / } \\
\text { Median (IQR)* }\end{array}$ & $\begin{array}{c}\text { Minimum - } \\
\text { Maximum }\end{array}$ \\
\hline Age (years) & $41 \pm 9$ & $20-50$ \\
\hline BMI (kg/m2) & $27 \pm 2$ & $22-32$ \\
\hline $\begin{array}{l}\text { Duration of marriage } \\
\text { (years) }\end{array}$ & $20.5 \pm 10.8$ & $0.2-40$ \\
\hline Parity & $3(2-5)^{*}$ & $0-10$ \\
\hline Abortions & $0(0-1)^{*}$ & $0-4$ \\
\hline
\end{tabular}

$\mathrm{SD}=$ standard deviation, $\mathrm{IQR}=$ interquartile range.

The abnormal uterine bleeding pattern Among the 114 patients, majority of the patients 39 cases (34.2\%) presented with complaints of menorrhagia, followed by postmenopausal bleeding 26 cases $(22.8 \%)$. Metroryhagia was present in $14.9 \%$ cases, menometrorrhagia in $12.5 \%$ cases, hypomenorrhea $10.5 \%$ cases, polymenorrhea $3.5 \%$ while oligomenorrhea seen in $2.2 \%$ of cases (Table 2). 
Table (2): Presenting symptom.

\begin{tabular}{|l|c|c|}
\hline \multicolumn{1}{|c|}{ Presenting symptom } & N & \% \\
\hline Menorrhagia & 39 & $34.2 \%$ \\
\hline Metrorrhagia & 17 & $14.9 \%$ \\
\hline Hypomenorrhea & 12 & $10.5 \%$ \\
\hline Menometrorrhagia & 14 & $12.3 \%$ \\
\hline Polymenorrhea & 4 & $3.5 \%$ \\
\hline Oligomenorrhea & 2 & $2.2 \%$ \\
\hline Postmenopaual bleeding & 26 & $22.8 \%$ \\
\hline & 114 & $\%$ \\
\hline
\end{tabular}

Data are number $(\mathrm{N})$ and percentage $(\%)$.

Data From Office Hysteroscopy $(\mathrm{OH})$ and Data From The Histopathological Study (Definitive Diagnosis - Gold Standard):

Data finding by office hysteroscopy from the uterine cavity of all pre and postmenopausal women included in the study were; 28 cases (23.4\%) had endometrial polyps, 31 (27\%) cases had endometrial hyperplasia, 6 cases $(5.4 \%)$ had submucous myomas, only 4 case $(2 \%)$ had endometrial carcinoma, 6 cases $(5.4 \%)$ had endocervical polyps and 39 cases $(34.2 \%)$ were normal (Table 3).

The definite diagnosis of the intrauterine lesions among the participants was obtained from the histopathological study of all cases, which is considered as the gold standard for the diagnosis of these lesions. We found that there were; 24 endometrial polyp (19.8\%), 33 endometrial hyperplasia (28.8\%), 7 submucous myoma (6.3\%), 7 endometrial carcinoma (6.3\%), 6 endocervical poly $(5.4 \%)$ and 37 normal (dysfunctional uterine bleeding) (33.3\%) (Table 3).

Table (3): Summary of hysteroscopic and histopathological findings

\begin{tabular}{|l|c|c|c|c|}
\hline & \multicolumn{2}{|c|}{$\begin{array}{c}\text { Hysteroscopy } \\
(\mathbf{n = 1 1 4})\end{array}$} & \multicolumn{2}{c|}{$\begin{array}{c}\text { Histopathology } \\
(\mathbf{n = 1 1 1})\end{array}$} \\
\hline Finding & $\mathrm{N}$ & $\%$ & $\mathrm{~N}$ & $\%$ \\
\hline Endocervical polyp & 6 & $5.4 \%$ & 6 & $5.40 \%$ \\
\hline Endometrial polyp & 28 & $23.4 \%$ & 24 & $19.8 \%$ \\
\hline Submucous myoma & 7 & $6.3 \%$ & 7 & $6.3 \%$ \\
\hline Endometrial hyperplasia & 31 & $27 \%$ & 33 & $28.8 \%$ \\
\hline $\begin{array}{l}\text { Endometrial } \\
\text { adenocarcinoma }\end{array}$ & 4 & $3.6 \%$ & 7 & $6.3 \%$ \\
\hline Normal & 38 & $34.2 \%$ & 37 & $33.3 \%$ \\
\hline
\end{tabular}

Data are number $(\mathrm{N})$ and percentage $(\%)$.

Correlation Of the Findings Of Office Hysteroscopy $(\mathrm{OH}) \mathrm{To}$ The Definitive Diagnosis (Histopathology):

We correlated the findings of office hysteroscopy $(\mathrm{OH})$ to the findings of the histopathology (HP), which is the gold standard for the diagnosis of the intrauterine lesions, and we found that; (Table 4).

Table (4): Hysteroscopic findings cross-tabulated versus histopathological findings

\begin{tabular}{|c|c|c|c|c|c|c|c|c|}
\hline & \multicolumn{7}{|c|}{ Hysteroscopy } \\
\hline & & \begin{tabular}{|c|}
$\begin{array}{c}\text { Endocervical } \\
\text { polyp }\end{array}$ \\
\end{tabular} & \begin{tabular}{|c|}
$\begin{array}{c}\text { Endometrial } \\
\text { polyp }\end{array}$ \\
\end{tabular} & \begin{tabular}{|c|}
$\begin{array}{c}\text { Submucous } \\
\text { myoma }\end{array}$ \\
\end{tabular} & $\begin{array}{l}\text { Endometrial } \\
\text { hyperplasia }\end{array}$ & $\begin{array}{c}\text { Endometrial } \\
\text { adenocarcinoma }\end{array}$ & Normal & Total \\
\hline \multirow{7}{*}{ 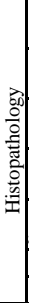 } & $\begin{array}{c}\text { Endocervical } \\
\text { polyp }\end{array}$ & 6 & 0 & 0 & 0 & 0 & 0 & 6 \\
\hline & $\begin{array}{c}\text { Endometrial } \\
\text { polyp }\end{array}$ & 0 & 22 & 0 & 0 & 0 & 2 & 24 \\
\hline & $\begin{array}{c}\text { Submucous } \\
\text { myoma }\end{array}$ & 0 & 0 & 6 & 0 & 0 & 1 & 7 \\
\hline & $\begin{array}{l}\text { Endometrial } \\
\text { hyperplasia }\end{array}$ & 0 & 1 & 0 & 29 & 0 & 3 & 33 \\
\hline & $\begin{array}{c}\text { Endometrial } \\
\text { adenocarcinoma }\end{array}$ & 0 & 1 & 0 & 2 & 4 & 0 & 7 \\
\hline & Normal & 0 & 4 & 1 & 0 & 0 & 32 & 37 \\
\hline & Total & 6 & 28 & 7 & 31 & 4 & 38 & 114 \\
\hline
\end{tabular}

Data are counts.

The accuracy of diagnostic hysteroscopy in the detection of an intrauterine lesion in cases of abnormal uterine bleeding; the $(\mathrm{OH})$ diagnosed 70 cases of intrauterine lesions which were confirmed by histopathology (true positive), while histopathology excluded 5 normal cases which were diagnosed falsely as intrauterine lesions by hysteroscopy (false positive). In other hand, 6 cases with intrauterine lesions ( 2 cases with endometrial polyps, 3 with endometrial hyperplasia and 1 with submucous myoma) were excluded falsely by hysteroscopy (false negative) (Table 5).

Table (5): Accuracy of hysteroscopy for diagnosis of intrauterine lesion in patients with abnormal uterine bleeding

\begin{tabular}{|l|c|c|c|}
\hline \multirow{2}{*}{ Hysteroscopy } & \multicolumn{2}{|c|}{ Histopathology } & \multirow{2}{*}{ Total } \\
\cline { 2 - 3 } & $\begin{array}{c}\text { Intrauterine } \\
\text { lesions }\end{array}$ & $\begin{array}{c}\text { No intrauterine } \\
\text { lesions }\end{array}$ & \\
\hline Intrauterine lesions & 70 & 5 & 75 \\
\hline No intrauterine lesions & 6 & 33 & 39 \\
\hline Total & 76 & 38 & 114 \\
\hline Statistic & Value & $\begin{array}{c}\text { Lower bound } \\
(95 \%)\end{array}$ & $\begin{array}{c}\text { Upper } \\
\text { bound } \\
(95 \%)\end{array}$ \\
\hline Correct classification & $90.1 \%$ & $84.5 \%$ & $95.6 \%$ \\
\hline Misclassification & $9.9 \%$ & $4.4 \%$ & $15.5 \%$ \\
\hline Sensitivity & $91.9 \%$ & $83 \%$ & $96.5 \%$ \\
\hline Specificity & $86.5 \%$ & $71.4 \%$ & $94.4 \%$ \\
\hline False positive rate & $13.5 \%$ & $3.0 \%$ & $24.0 \%$ \\
\hline False negative rate & $8.1 \%$ & $2.1 \%$ & $14.2 \%$ \\
\hline Prevalence & $66.7 \%$ & $57.9 \%$ & $75.4 \%$ \\
\hline $\begin{array}{l}\text { Positive predictive } \\
\text { value }\end{array}$ & $93.2 \%$ & $87.4 \%$ & $98.9 \%$ \\
\hline $\begin{array}{l}\text { Negative predictive } \\
\text { value }\end{array}$ & $84.2 \%$ & $72.6 \%$ & $95.8 \%$ \\
\hline $\begin{array}{l}\text { Positive likelihood } \\
\text { ratio }\end{array}$ & 6.8 & 3,00 & 15.41 \\
\hline $\begin{array}{l}\text { Negative likelihood } \\
\text { ratio }\end{array}$ & 0.09 & 0,04 & 0,20 \\
\hline Relative risk & 5.9 & 2.92 & 11.92 \\
\hline Odds ratio & 72.53 & 21.63 & 243.20 \\
\hline
\end{tabular}




\section{DISCUSSION}

Abnormal uterine bleeding is one of the leading causes of seeking gynecological advice. The causes of Abnormal Uterine Bleeding and its differential diagnosis are heterogeneous and complex. Hysteroscopy has ushered a new era in the evaluation of abnormal uterine bleeding. By direct visualization of uterine cavity, hysteroscopy is able to pin point the etiology ${ }^{(\mathbf{1 2})}$.

Hysteroscopy should ideally be done in all cases where a transvaginal ultrasound reveals a thickened endometrium or intrauterine lesions ${ }^{(13)}$.

Diagnostic hysteroscopy is a commonly performed gynecologic procedure to evaluate the endometrial cavity. Broadly, systems of diagnostic hysteroscopy exist: Panoramic and Contact ${ }^{(3)}$.

Hysteroscopy has been proved to be the definite method for evaluation of the uterine cavity and diagnosis of associated abnormalities ${ }^{(\mathbf{1 4})}$.

The major limitation to hysteroscopy is providing subjective assessment for the size of a lesion and the depth of myometrial extension of myomas, also needs a good experience ${ }^{(15)}$.

In our study, the age group was 20-50 years. The maximum incidence of AUB was found between $41+/-9$ years with the youngest patient being 20 years and oldest patient 50 years old; these findings are being supported by Sangeeta Series (6) in which maximum age incidence was between 31-50 years (56\%) and Dirgha series ${ }^{(8)}$ in which maximum age incidence was between $31-50$ years $(42.7 \%)$. The commonest presenting complaint in this series was menorrhagia (39\%) followed by postmenopausal bleeding (26\%) followed by metrorrhagia (17\%). These findings are supported by Phalak et al. (9) series in which $60 \%$ of the cases had menorrhagia and Aisha and Shukar-ud-Din ${ }^{(16)}$ series in which menorrhagia was seen in $38.8 \%$ cases.

Of all the 114 cases which enrolled into present study, the commonest pathology was seen on the hysteroscopy is: Endometrial hyperplasia which was seen in 33 cases $(27 \%)$ followed by endometrial polyps 28 cases $(23.4 \%)$ and submucous myoma 7cases $(5.4 \%)$; these findings are being supported by Phalak et al. ${ }^{(9)}$ series in which hyperplasia was found in $40 \%$ cases. Polyps were found in $32 \%$ cases, and submucous fibroids were seen in $8 \%$ cases.
In our study, histopathology showed abnormal findings in 76 cases $(66.6 \%)$. Of these, 33 cases $(28.8 \%)$ had hyperplasia, 24 cases (19.8\%) had polyps and 7 case had submucouse myoma; these findings are in accordance with Phalak et al. ${ }^{(9)}$ in which abnormal histopathology findings were present in $44 \%$ cases of which $45.46 \%$ cases had hyperplasia, $27.27 \%$ cases had polyps and $9.09 \%$ cases had submucosal fibroids and Aisha and Shukar-ud-Din ${ }^{(16)}$ series in which histopathology detected abnormalities in $60 \%$ cases of which hyperplasia was present in $20 \%$ cases, polyps in $18.8 \%$ cases and fibroids in $11.3 \%$ cases.

Of the 38 cases which had normal endometrium on hysteroscopy in present study, 33 patients had normal endometrium on histopathology as well, 3 cases had hyperplasia, 2 cases had endometrial polyps and 1cases with submucous myoma detected on histopathology. Statistically, true positives were 70 , false positives 5 , true negatives 33 and false negatives were 6. By calculating these data, hysteroscopy had a sensitivity of $91.9 \%$, specificity of $86.5 \%$, positive predictive value of $93.2 \%$, negative predictive value of $84.2 \%$ and diagnostic accuracy of $90.1 \%$ for diagnosing etiology of abnormal uterine bleeding; These results are being supported by Phalak et al. ${ }^{(9)}$ series which showed hysteroscopy to have a sensitivity of $95.65 \%$, specificity of $88.46 \%$, positive predictive value of $88 \%$, negative predictive value of $95 \%$ and diagnostic accuracy of $91.84 \%$ and Pop Trajković Dinić et al. ${ }^{(17)}$ series in which hysteroscopy had a sensitivity of $100 \%$ in the detection of intrauterine pathology, specificity of $81 \%$, the positive predictive value of $92 \%$ and the negative predictive value of $100 \%$.

In our Study, 31 cases diagnosed as hyperplasia by hysteroscopy. Among them, 29 had hyperplasia on histopathology as well; while 2 patients had endometrial adenocarcinoma in histopathological examination. Hence, true positives were 29 , false positives 2 , false negatives 4 and true negatives 77. Accordingly hysteroscopy had a sensitivity of $87.8 \%$, specificity of $97.5 \%$, positive predictive value of $93.5 \%$, negative predictive value of $95.1 \%$ and accuracy of $94.6 \%$; these findings are being supported by Torrejon et al. ${ }^{(\mathbf{1 8})}$ series in which sensitivity was $71.8 \%$ and specificity $96.4 \%$.

Of the 28 cases showing endometrial polyps on hysteroscopy, histopathology detected 22 cases and 4 cases were described as normal, 1case 
endometrial hyperplasia and 1 case endometrial adenocarcinoma. Thereby, true positives were 22, false positives 6 , false negative 2 and true negatives 84 . Hence hysteroscopy had a sensitivity of $90.9 \%$, specificity of $93.3 \%$, positive predictive value of $76.9 \%$, negative predictive value of $97.6 \%$ and accuracy of $92.8 \%$. These findings are being supported by Tajossadat and Fereshteh ${ }^{(\mathbf{1 9 )}}$ series in which hysteroscopy had a sensitivity of $93 \%$, specificity of $100 \%$, positive predictive value of $100 \%$, and negative predictive value of $95.4 \%$ in diagnosing endometrial polyps.

Of the 7 cases showing submucous myoma on hysteroscopy, histopathology detected 6 cases and 1 case were described as normal. Thereby, true positives were 6 , false positives 1 , false negative 1 and true negatives 106 . Hence hysteroscopy had a sensitivity of $85.7 \%$, specificity of $99.0 \%$, positive predictive value of $85.7 \%$, and negative predictive value of $99.0 \%$ and accuracy of $98.2 \%$. These findings are being supported by Tajossadat and Fereshteh ${ }^{(19)}$ series in which hysteroscopy had a sensitivity of $93 \%$, specificity of $100 \%$, positive predictive value of $100 \%$, and negative predictive value of $95.4 \%$ in diagnosing submucous myoma.

\section{CONCLUSION}

This study confirms that hysteroscopy has a definitive role in evaluating patients with abnormal uterine bleeding especially with patient with thick endometrium and in any age group. Hysteroscopy is a safe and reliable procedure in the diagnosis of cases with abnormal uterine bleeding with high sensitivity, specificity, positive predictive value and negative predictive value and the results of hysteroscopy are immediately available. Hysteroscopy and histopathology complement each other in evaluating patients with abnormal uterine bleeding for accurate diagnosis and further treatment.

\section{RECOMMENDATION}

More studies are necessary to determine hysteroscopic characteristics of the hidden hyperplasia and endometrial neoplasm. Hysteroscopist should be trained to differentiate visual appearances that suggest atypical to allow a more accurate biopsy of the suspicious area. Hysteroscopy remains the gold standard for assessment of the uterine cavity especially with patient with thick endometrium, but can't replace the histopathology.

\section{REFERENCES}

1- Khrouf M and Terras K (2014): Diagnosis and management of formerly called "dysfunctional uterine bleeding" according to PALMCOEIN FIGO classification and the new guidelines. J Obstet Gynaecol India, 64 (6):38893.

2- Singh RH and Blumenthal $P$ (2005): Hormonal management of abnormal uterine bleeding. Clinical Obstetrics and Gynecology, 48(2):337-52.

3- Sharma JB and Yadav M (2013): New ground breaking International Federation of Gynecology and Obstetrics's classification of abnormal uterine bleeding: Optimizing management of patients. J Midlife Health, 4(1):42-5.

4- $\quad$ Rezk M, Masood A and Dawood R (2015): Perimenopausal bleeding: Patterns, pathology, response to progestins and clinical outcome. J Obstet Gynaecol., 35 (5):51721.

5- ACOG (2012): Practice Bulletin No. 128. Diagnosis of abnormal uterine bleeding in reproductive-aged women. Obstet Gynecol., 120:197-206.

6- Mukhopadhyay SR and Ashis K (2014): Correlation between Diagnostic Hysteroscopy And Its Histopathological Examination In The Evaluation Of Abnormal Uterine Bleeding. Indian J Prev Soc Med., 45:1-2.

7- Shruti M and Page LM (2007): Diagnosis of abnormal uterine bleeding. Best Practice and Research Clinical Obstetrics and Gynaecology, 21(6):891-903.

8- Firdous N, Mukhtar S, Bilal S and Beigh SK (2018): Role of hysteroscopy and histopathology in evaluating patients with abnormal uterine bleeding. International Journal of Reproduction, Contraception, Obstetrics and Gynecology, 6(2):615-9.

9- Phalak R Rawal $R$ and Mule VD (2015): Hysteroscopy as a Diagnostic Aid in Gynecology, International Journal of Interdisciplinary and Multidisciplinary Studies, 2(10):78-83. 
10- Malhotra RK and Indrayan A (2010): A simple nomogram for sample size for estimating sensitivity and specificity of medical tests. Indian J Ophthalmol., 58:51922.

11- Firdous N, Mukhtar S, Bilal S and Beigh SK (2017): Role of hysteroscopy and histopathology in evaluating patients with abnormal uterine bleeding. Int $\mathrm{J}$ Reprod Contracept Obstet Gynecol., 6:615-9.

12- Sunitha $C$ and Somalatha $R$ (2013): Clinical study of diagnostic hysteroscopy in abnormal uterine bleeding and its histopathological correlation. IOSR Journal of Dental and Medical Sciences, 5(3):43-6.

13- Jeffcoate's Principles of Gynaecology (1998): Eighth Edition, Narendra Malhotra, Pratap Kumar, Abnormal and Excessive Uterine Bleeding, 569.

14- Shushan A and Rojansky N (1999): Should hysteroscopy be a part of the basic infertility workup? Hum Reprod., 14: 1923-4.

15- Makris N, Kalmantis $K$, Skartados $N$ et al. (2006): Three dimensional hysterosonography versus hysteroscopy for the detection of intracavitary uterine abnormalities. Int $\mathbf{J}$ Gynecol Obstet., 97:6-9.
16- Razzaq A and Shukar-ud-Din S (2011): Role of diagnostic hysteroscopy in case of abnormal uterine bleeding Pak J Surg., 27(4):309-15.

17- Pop Trajković Dinić S, Ljubić A, Kopitović V (2013): The role of hysteroscopy in diagnosis and treatment of postmenopausal bleeding. Vojnosanit Pregl., 70(8): 747-50.

18- Torrejon R, Fernandez-Alba JJ, Carnicer I and Martin A (1997): The value of hysteroscopic exploration for abnormal uterine bleeding. J Am Assoc Gynecol Laparosc., 4(4):453-6.

19- Tajossadat A and Fereshteh $M$ (2007): Diagnostic value of hysteroscopy in abnormal uterine bleeding compared to pathology reports. Iranian Journal of Reproductive Medicine, 5(2):61-4. 